\title{
DEVELOPMENT OF A KIND OF FLAVORING TABLETS FOR
}

\section{CHILDREN'S USE}

\author{
Chen Liu ${ }^{1}$, Haiyan Cao ${ }^{1}$, Linfeng Li ${ }^{1}$, Ruomei Che ${ }^{1}$, Zihui Li ${ }^{1}$, Guowei Zhang ${ }^{1}$ * \\ ${ }^{1}$ Department of Traditional Chinese Medicine, Hebei University, Baoding, China
}

\section{ABSTRACT}

Objective: In this study, based on children's medication preferences, Synsepalum dulcificum and Siraitia grosvenorii as raw material were used to develop a flavoring medicine for children.

Methods: Synsepalum dulcificum and Siraitia grosvenorii as the raw material were applied to extract the Synsepalum dulcificum powder and Siraitia grosvenorii powder respectively, according to the orthogonal test design; the optimal proportion of flavoring powder was obtained. Low-substituted hydroxypropyl cellulose(L-HPC), polyvinylpolypyrrolidone(PVPP), sodium carboxymethyl starch(CMS-Na), microcrystalline cellulose(MCC) were taken, according to the orthogonal test design the optimum proportion of auxiliary materials, then the flavoring tablets was prepared according to the preparation process.

Results: Through orthogonal test design, the optimum ratio of Synsepalum dulcificum: Siraitia grosvenorii was 1:3, and mixing them up in proportion; the optimum ratio of L-HPC: PVPP: CMS-Na: MCC was 10: 8: 3: 6, and mix them up in proportion. Equal amounts of sugar and salt were obtained by mass ratio of 1 to 1 . Mixing 1/3 amount of flavoring powder with 3/4 amount of auxiliary materials, using $20 \%$ ethanol as a wetting agent, using the remaining sugar as a filler, and granulating. After the granules were dried and whole grain, add the remaining auxiliary materials and magnesium stearate were added, then the flavoring tablets were prepared.

Conclusion: The effects of this formula were prominent, which could effectively intervene the taste of children's medicine; solve the practical problems concerning taking medications in children.

Keywords: Synsepalum dulcificum; Siraitia grosvenorii; drug use in children; flavoring tablets

Article Info: Received 22 March, 2018; Review Completed 11 April 2018; Accepted 12 April 2018; Available online 15 May 2018

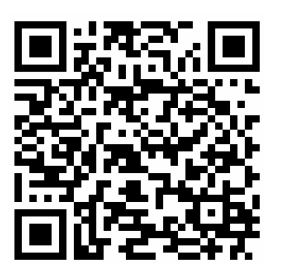

Cite this article as:

Liu C, Cao H, Li L, Che R, Li Z, Zhang G, Development of a kind of flavoring tablets for children's use, Journal of Drug Delivery and Therapeutics. 2018; 8(3):14-19 DOI: http://dx.doi.org/10.22270/jddt.v8i3.1755

*Address for Correspondence:

Guowei Zhang, Department of Traditional Chinese Medicine, Hebei University, Baoding, China. 


\section{INTRODUCTION}

Most drugs, especially traditional Chinese medicine, have poor taste, often bitter, astringent, acid and other unpleasant taste, which can cause taste discomfort and even vomiting. Especially the child patient, because their taste buds are more widely distributed, they are more sensitive to taste. When the compliance of the drug is poor, treatment is always delayed, because children are not willing to take, so this limits the use in children. By using the technique of flavoring, it can improve or block the effects of bad taste in drugs, and then improve the compliance of the patients ${ }^{1}$. So, it is especially important to use flavoring and taste-masking techniques to improve the unpleasant taste of drugs to within acceptable levels, which has been more and more concerned by researchers ${ }^{2}$. In order to make good medicine no longer bitter, under the unremitting efforts of research workers, a number of innovative flavoring and taste-masking technologies continue to emerge $e^{3-5}$. Although there are currently some techniques and methods of flavoring, due to the complexity of traditional Chinese medicine ingredients, most methods are unable to effectively play a good role, or difficult to achieve industrial production. After research, the vast majority of currently marketed medicines still use traditional flavoring methods such as adding flavoring agents ${ }^{6}$. However, most of the flavoring agent and flavoring techniques have poor flavoring effects, or does not apply to children's medicine, so there are no major advances in the use of flavoring agent and flavoring techniques for children's medications.

Based on children's medication preferences, in this experiment flavoring powder was made from Synsepalum dulcificum and Siraitia grosvenorii, and used the new disintegrant and diluent as excipients to prepare children's medications. Its preparation process is simple, suitable for industrial production, has good application prospects and greater social and economic benefits.

\section{INSTRUMENTS AND MATERIALS}

\section{Instruments}

High-speed homogenizer(PT 2100 POLYTRON), rotatory evaporator(RE-2000, Shanghai Ya Rong biochemical instrument factory), single punch tablet machine (TP-1400, Shanghai Tianfeng Pharmaceutical
Equipment Co., Ltd.), pure water machine (PURELAB ELGA), low temperature drying box ( BK-1000H Dongguan Qinzhuo Environmental Testing Equipment Co., Ltd. ) , balance (FA1104 Shanghai Fangrui Instrument Co., Ltd.) and so on.

\section{Materials}

Synsepalum dulcificum(certified by Liang Xianmao as a genuine product), Siraitia grosvenorii(certified by Liang Xianmao as a genuine product), L-HPC (Hangzhou general biological technology Co. Ltd, batch number: PS41809), PVPP (Hangzhou general biological technology Co. Ltd., batch number: PS41853), CMS-Na (Hangzhou general biological technology Co. Ltd., batch number: PS41839), ethanol and MCC (Hangzhou general biological technology Co. Ltd., batch number: PS41306).

\section{METHODS AND RESULTS}

\section{Extraction process of Synsepalum dulcificum}

Weigh the Synsepalum dulcificum and wash them with pure water, grind them into small pieces with a mortar and pestle. Transfer the ground fruit to a small beaker; add equal volume of pure water. Using the homogenizer to homogenize the Synsepalum dulcificum to uniform color, and make the particles in the solution even and detailed, then vacuum filtration with a vacuum pump, precipitate the white powder solid in the filtrate body, and pour out the supernatant. The remaining turbid liquid continues to filter, until no obvious white precipitate. The slurry is dried under reduced pressure at a temperature of less than $50^{\circ} \mathrm{C}$, then ultrafine grinding, get the Synsepalum dulcificum powder.

\section{Extraction process of Siraitia grosvenorii}

Remove the dust from the surface and weigh the Siraitia grosvenorii with a balance. After rinsing it with pure water and breaking the shell into the pot, add pure water just to drown all the fruit. Heat the fire to a boil, turn to a small fire and heat for 30 minutes, the first filtrate was obtained after filtration. Then continue adding pure water to the pot, and for the first time, continue to heat for 30 minutes, get the second filtrate. The last time add no more than the first two pure water and continue to heat for 15 minutes. Combine the three filters, heat and then vaporize and then condense, until the thick, dark brown liquid extract is obtained. After decompression and drying, the 
fluid extract was pulverized and the fruit powder was obtained.

The best proportion choice and correction characteristic score of the Synsepalum dulcificum and Siraitia grosvenorii

According to the ratio of the Synsepalum dulcificum powder and the Siraitia grosvenorii powder in the orthogonal experiment, it is shown in table 1. Randomly selected 10 subjects, the four proportions of the fruit powder and the score list were distributed to 10 subjects. Subjects were asked to rate the correction characteristics of the correction powder according to their related senses. After the experiment, we summarized and analyzed the correction film score.
Table 1: Formulation factor level

\begin{tabular}{ccc}
\hline level & $\begin{array}{c}\text { Synsepalum } \\
\text { dulcificum }\end{array}$ & $\begin{array}{c}\text { Siraitia } \\
\text { grosvenorii }\end{array}$ \\
\hline 1 & 3 & 2 \\
2 & 1 & 3 \\
\hline
\end{tabular}

According to the taste of 10 people, and according to the sensory quality score standard of correctional powder, as shown in table 2. Full mark 20. The result was the fruit of the Synsepalum dulcificum (fresh fruit): Siraitia grosvenorii (dried fruit) $=1: 3$, the correction characteristics (acid) and correction characteristics (bitter) were all 8 points.

Table 2: Taste masking characteristic scoring criteria of children's medication taste masking powder

\begin{tabular}{lll}
\hline $\begin{array}{l}\text { correction characteristics (acid) } \\
\begin{array}{l}\text { The taste of sour food in 2h-4h was } \\
\text { significantly sweeter. }\end{array}\end{array}$ & $\begin{array}{l}\text { The bitter taste of the bitter solution is lost or almost lost, } \\
\text { and there is a residual sweetness. }\end{array}$ & a weighted score \\
\hline $\begin{array}{l}\text { The taste of sour food in 2h was } \\
\text { significantly sweeter. }\end{array}$ & $\begin{array}{l}\text { The bitter taste of the bitter solution was greatly reduced, } \\
\text { with slight bitter taste and slightly sweet. }\end{array}$ \\
\hline $\begin{array}{l}\text { In 1h-2h, the taste of sour food is } \\
\text { sweetened. }\end{array}$ & $\begin{array}{l}\text { The bitterness of the bitter solution was significantly } \\
\text { reduced, and the taste was bitter and the sweetness was not } \\
\text { obvious. }\end{array}$ \\
\hline $\begin{array}{l}\text { In 1h, the taste of sour food } \\
\text { becomes sweet. }\end{array}$ & $\begin{array}{l}\text { The second time the bitterness of the bitter solution } \\
\text { decreased, but it was obvious that there was no sweetness. }\end{array}$ \\
\hline It was not obvious to eat sour taste. & $\begin{array}{l}\text { Drink bitter solution is still very bitter, taste masking effect } \\
\text { is not obvious. }\end{array}$ \\
\hline
\end{tabular}

\section{The prescription optimization}

Through orthogonal experiment, the best formula technology of correctional film was selected. With
L-HPC, CMS-N and PVPP as disintegrating agents, MCC was the diluent and adhesives, list table 3 in terms of quality.

Table 3: Prescription optimization factor level

\begin{tabular}{ccccc}
\hline level & L-HPC (A) & CMS-Na (B) & PVPP (C) & MCC (D) \\
\hline 1 & 9 & 5 & 3 & 5 \\
2 & 10 & 6 & 4 & 6 \\
3 & 11 & 7 & 5 & 7 \\
4 & 12 & 8 & 6 & 8 \\
\hline
\end{tabular}

The preparation and screening of taste masking tablets and sensory quality score
(1) The design weight was $250 \mathrm{mg}$, each tablet contains $125 \mathrm{mg}$ of correctional powder. 
(2) Weigh 45 grams of corrective powder, through 100 mesh sieve. Set the Oven to $60{ }^{\circ} \mathrm{C}$ for drying at constant temperature. Take it $40 \mathrm{~g}$, According to the proportion of quality, L-HPC, CMS-Na, PVPP, MCC (dry before use) were $40 \mathrm{~g}$ and through 80 mesh sieve, mix $1 / 3$ of the mixture with 3/4 L-HPC, CMS-Na, PVPP and MCC.

(3) With $20 \%$ ethanol as the wetting agent, the remaining mixture is the filling agent, sieve the granules with 16 mesh.

(4) Ovens for $60{ }^{\circ} \mathrm{C}$ constant temperature drying, after drying, pass 20 mesh screen.

(5) Take out the dried grains, add the remaining 1/4 auxiliary materials L-HPS, CMS -na, PVPP, MCC, and magnesium stearate with a total quality of $2 \%$, tablet.

(6) Six tablets of each group were taken and placed in the glass tube with a hanging basket of the disintegrating instrument, one piece per tube, add baffle, immersed in a
$1000 \mathrm{~mL}$ beaker, inside the beaker containing temperature $(37+1){ }^{\circ} \mathrm{C}$ water. Adjust the height of the water level so that the net is $25 \mathrm{~mm}$ from the bottom of the beaker. When the basket rises, the screen is $25 \mathrm{~mm}$ below the surface of the water. When the bracket is moved, the distance is (55 plus or minus 2 ) $\mathrm{mm}$, the reciprocating frequency is $30 \sim 32$ times per minute. If one is not fully disintegrated, six retries should be taken; all should be screened in the specified time.

In accordance with the orthogonal test, through the taste of 10 people, according to the sensory quality score criteria of the children's drug correction tablets, as shown in table 4 , the full score is 40 , the result is that the optimal condition of the correction film is $\mathrm{A}_{2} \mathrm{~B}_{4} \mathrm{C}_{1} \mathrm{D}_{2}$, that the highest score is L-HPC: CMS-Na: PVPP: MCC $=10.8: 3: 6$. The exterior color is 10 points, the flavor is 8 points, the correction characteristics (acid) and correction characteristics (bitter) were all 8 points.

Table 4: Sensory quality scoring criteria for children's drug correction tablets

\begin{tabular}{|c|c|c|c|c|}
\hline $\begin{array}{l}\text { exterior } \\
\text { colour and } \\
\text { luster }\end{array}$ & taste and mouth feel & $\begin{array}{l}\text { correction } \\
\text { characteristics (acid) }\end{array}$ & correction characteristics (bitter) & $\begin{array}{l}\text { a } \\
\text { weighted } \\
\text { score }\end{array}$ \\
\hline $\begin{array}{l}\text { yellowish-b } \\
\text { rown }\end{array}$ & $\begin{array}{l}\text { The entrance is easy to } \\
\text { thaw and sweet. }\end{array}$ & $\begin{array}{l}\text { The taste of sour } \\
\text { food in } 2 \mathrm{~h}-4 \mathrm{~h} \text { was } \\
\text { significantly } \\
\text { sweeter. }\end{array}$ & $\begin{array}{l}\text { The bitter taste of the bitter } \\
\text { solution is lost or almost lost, and } \\
\text { there is a residual sweetness. }\end{array}$ & 10 \\
\hline $\begin{array}{l}\text { pale yellow } \\
\text { brown }\end{array}$ & $\begin{array}{l}\text { Into the mouth } \\
\text { relatively easy to } \\
\text { thaw, no sticky mouth, } \\
\text { no granular sensation. }\end{array}$ & $\begin{array}{l}\text { The taste of sour } \\
\text { food in } 2 \mathrm{~h} \text { was } \\
\text { significantly } \\
\text { sweeter. }\end{array}$ & $\begin{array}{l}\text { The bitter taste of the bitter } \\
\text { solution was greatly reduced, with } \\
\text { slight bitter taste and slightly } \\
\text { sweet. }\end{array}$ & 8 \\
\hline yellow & $\begin{array}{l}\text { Into the mouth a little } \\
\text { bit sticky mouth, no } \\
\text { granular sensation, a } \\
\text { bit rough. }\end{array}$ & $\begin{array}{l}\text { In } 1 \mathrm{~h}-2 \mathrm{~h}, \text { the taste of } \\
\text { sour food is } \\
\text { sweetened. }\end{array}$ & $\begin{array}{l}\text { The bitterness of the bitter } \\
\text { solution was significantly } \\
\text { reduced, and the taste was bitter } \\
\text { and the sweetness was not } \\
\text { obvious. }\end{array}$ & 6 \\
\hline light yellow & $\begin{array}{l}\text { Relatively sticky } \\
\text { mouth, a little bit } \\
\text { granular sensation, } \\
\text { feeling rough. }\end{array}$ & $\begin{array}{l}\text { In } 1 \mathrm{~h}, \text { the taste of } \\
\text { sour food becomes } \\
\text { sweet. }\end{array}$ & $\begin{array}{l}\text { The second time the bitterness of } \\
\text { the bitter solution decreased, but } \\
\text { it was obvious that there was no } \\
\text { sweetness. }\end{array}$ & 4 \\
\hline white & $\begin{array}{l}\text { Feeling rough, sticky } \\
\text { mouth, the heavier } \\
\text { granular sensation. }\end{array}$ & It's not obvious. & $\begin{array}{l}\text { Drink bitter solution is still very } \\
\text { bitter, taste masking effect is not } \\
\text { obvious. }\end{array}$ & 2 \\
\hline
\end{tabular}




\section{Quality inspection of corrective tablets}

Prepare a set of correction tablets and conduct quality inspection according to the best process.

Quality inspection method: according to the 2015 edition of the pharmacopoeia of the People's Republic of China, check the appearance, weight difference and brittle degree of a group with the shortest disintegrating time. And the sensory quality was graded according to 3.5 .

(1) Appearance: clean and neat, uniform color, suitable for hardness.

(2) Weight difference: The total quality of 10 tablets is $2.508 \mathrm{~g}$. The average weights was $0.251 \mathrm{~g}$. The number of pills exceeding the weight limit is 0 , the number of pills that exceed the limit of 1 is 0 . Therefore, the weight difference examination is qualified.

(3) Brittle broken degrees: Before the experiment, the total quality of 10 tablets was $2.518 \mathrm{~g}$. After the test, it was 2.498g. Brittleness $=(2.518-2.498 / 2.518 *$ $100 \%=0.79 \%<0.8 \%$ ), the brittleness is qualified.

(4) Sensory quality score: According to the taste of 10 people, The exterior color is 10 points, the flavor is 8 points, the correction characteristics (acid) and correction characteristics (bitter) were all 8 points.

\section{DISCUSSION}

In the general trend of the development of flavorings and taste maskers, Children as taste sensitive and very emotional groups, children's sense of taste for the drug is bound to cause widespread concern.

Siraitia grosvenorii is an economic and medicinal plant peculiar to China. It is a traditional specialty of Guangxi in Guangxi. Siraitia grosvenorii have high nutritional value, rich in fructose, protein and vitamins, it cool and sweet, can moisten lung to arrest cough, clearn away heat and toxic material, relieve cough and reducing sputum, and it has an inhibitory effect on inflammation such as respiratory tract ${ }^{7}$. Siraitia grosvenorii contains low-calorie sweet ingredients mogroside, sweetness of sucrose 260 times, calorie only 1/50 of sucrose, and have a certain role in lowering blood sugar ${ }^{\mathbf{8}}$. Sweet like stevia, without any after-taste, fragrant and delicious, is the ideal natural sweetener. Synsepalum dulcificum pulp is nutritious and contains glycoproteins such as Vc, Vk1, citric acid, succinic acid, oxalic acid, $(\mathrm{R} *)$ 4-hydroxy-2-oxetanone and so on'. Mysterious fruit has a unique taste-changing activity, adding it to low-sugar sweets can not only increase the aroma sweet taste, but also effectively limit the energy intake ${ }^{10}$, Brouwer ${ }^{11}$ and other people to extract the mysterious fruit only $0.1 \mathrm{mg}$ has the ability to change the flavor of the function; Giroux $^{12}$ and other people get the concentrate only 0.02 mg can cause sweet. Because of this characteristic, people in the current food industry also use it as a flavoring agent. Therefore, in the field of medicine, Synsepalum dulcificum will have a broader development prospect due to its effect of improving the taste of medicines. Matching Synsepalum dulcificum and Siraitia grosvenorii, increase drug taste with low energy intake; it will play a very good role in children's drug use.

In this experiment, the preparation method of the drug-modified tablets was stated in detail, and the optimum proportion of Synsepalum dulcificum and Siraitia grosvenorii and the accessory were determined by orthogonal experiment. So the best proportion of children's drug-modified tablets is Synsepalum dulcificum (fresh Fruit): Siraitia grosvenorii (dried fruit) $=1: 3$ and the proportion of four kinds of excipients with L-HPC, PVPP, CMS-Na and MCC is 10:8:3:6. Judging from the scoring results, especially the characteristics of the taste, the modified tablets prepared in this experiment can intervene the taste feeling of the drug, especially the bitter medicine.

This modified tablet will be used in children's taste intervention, can effectively improve the taste of drugs; reduce the corresponding pain in children's medication. And combined with new disintegrating agent and thinner as excipient, it also has a good taste at the same time to improve the adaptability, so that the taste tablets can be more widely accepted by patients, especially children. The modified tablet is easy to produce, simple to prepare and suitable for industrial production, so it has good application prospect and greater social and economic benefits.

\section{CONCLUSION}

The best proportion of children's drug-modified tablets is Synsepalum dulcificum (fresh Fruit): Siraitia grosvenorii (dried fruit) $=1: 3$; Excipient formula for L-HPC: 
CMS-Na:PVPP:MCC=10:8:3:6(quality ratio), this formula can be used to effectively intervene the

\section{REFERENCES}

1. Douroumis D, Practical approaches of taste masking technologies in oral solid forms, Expert Opinion on Drug Delivery, 2007; 4(4):417-426.

2. Karaman R, Prodrugs for masking bitter taste of antibacterial drugs-a computational approach, J Mol Model, 2013; 19(6):2399-2412.

3. Sohi H, Sultana Y, Khar RK. Taste masking technologies in oral pharmaceuticals: Recent developments and approaches, Drug Dev Ind Pharm, 2004; 30(5):429-448.

4. Douroumis D. Practical approaches of taste masking technologies in oral solid forms. Expert Opin Drug Deliv, 2007; 4(4):417-26.

5. Ayenew Z, Puri V, Kumar L, et al.Trends in pharmaceutical taste masking technologies: A patent review, Recent Pat Drug Deliv Formul, 2009; 3(1):26-39.

6. Drašković M, Medarević D, Aleksić I, et al. In vitro and in vivo investigation of taste-masking effectiveness of Eudragit E PO as drug particle coating agent in orally disintegrating tablets. Drug Dev Ind Pharm, 2017; 43(5):723-731.

7. Shi DF, Wang YM, Chen S, et al. Protective effects and children's taste, and solve the problems concerning taking medicines in children.

mechanisms of mogroside V on LPS-induced acute lung injury in mice. Pharmaceutical Biology, 2014; 52(6):729-734.

8. Qi XY, Chen WJ, LIU L G, et al. Effect of a Siraitia grosevenori extract containing mogrosides on the cellular immune system of type 1 diabetes mellitus mice. Molecular Nutrition \& Food Research, 2006; 50(8):732-738.

9. Cheng $\mathrm{M} \mathrm{J}$, Lo W L, Huang $\mathrm{L} \mathrm{Y,} \mathrm{et} \mathrm{al.} \mathrm{Isolation} \mathrm{of} \mathrm{a}$ 2-oxetanone from the fruits of Synsepalum dulcificum. Nat. prod.res, 2010; 24(19):1850-1853.

10. Wong J M, Kern M' Miracle fruit improves sweetness of a lowcalorie dessert without promoting subsequent energy compensation. Appetite, 2011; 56(1):163-166.

11. Brouwer J N, van der Wel H, Francke A, et al. Miraculin, the sweetnessinducing protein from miracle fruit. Nature, 1968; 220(10):373-374.

12. Girous E L, Henkin R I. Purification and some properties of miraculin, a glycop rotein from Synsepalum dulificum which provokes sweetness and blocks sourness. J Agr Food Chem, 1974; 22(4):595-601. 